\title{
Transformer Oils Potential for PCBs Contamination
}

\section{Pelitli ${ }^{{ }^{*}}$, Ö. Doğan ${ }^{1}$ and H. J. Köroğlu ${ }^{2}$}

${ }^{1}$ The Scientific and Technological Research Council of Turkey, Marmara Research Center, Environment and Cleaner Production Institute, Kocaeli/ Turkey

${ }^{2}$ The Scientific and Technological Research Council of Turkey, Marmara Research Center, Institute of Chemistry, Kocaeli/Turkey

\begin{abstract}
Polychlorinated biphenyls (PCBs) are a class of synthetic organic chemicals consisting of from one to ten chlorine atoms bonded totwo phenyl rings that create up 209 possible variations referred to as congeners. PCBs were commercially produced world-wide on a large scale between the 1930s and 1980 sthat had been used widely in variety of commercial equipment like transformers, capacitors and other electrical equipment because of their useful quality as being a fire retardant. But due to their persistence and ubiquitous distribution in the environment, PCBs were banned from the U.S in the 1970s and internationally through the Stockholm Convention on Persistent Organic Pollutants. Although banned by law and punished heavily, large numbers of PCB-contaminated transformers are still in service. Thus, there remains a huge reservoir of PCBs with the potential to serve as sources of contamination to the environment. In this study, using EN 12766 test method: "Petroleum products and used oils-Determination of PCBs and related products", PCBs were analyzed in the random samples collected from different regions of Turkey. The samples also used for screening for the presence of total halogens and chlorine. Test results of the study showed that PCBs were present in certain transformers but concentrations in the most of samples did not exceed the limit value of $50 \mathrm{ppm}$.However, there was a significant relationship between the PCB concentrationsand the halogens.Finally, the contaminated transformer oils were evaluated according to Regulation on Control ofWaste Oils.
\end{abstract}

\section{Introduction}

POLYCHLORINATED biphenyls (PCBs) have been recognized as an environmental pollutant in 1966 when they were catalogued as hazardous waste [1]. PCB (CAS number 1336-36-3), C12H10$\mathrm{nCln}$, are manmade organic aromatic hydrocarbons that have 1 to 10 chlorine atoms attached to biphenyl, which is a molecule composed of two benzene rings each containing six carbon atoms [2]. The variable molecular composition of $\mathrm{PCB}$ allows different structural configurations due to possibility of different arrangements of chlorine atoms on the benzene rings of the PCB molecule. Theoretically, 209 different congeners (isomers), depending upon the number and positions of the chlorine atoms, are possible comprising the entire set of homologues and isomers, but only about 130 of these are likely to occur in commercial products [3]. All congeners of PCBs are lipophilic but different congeners sometimes act differently from one another and water solubility decreases as the degree of chlorination increases [4].

Previous studies revealed that the $\mathrm{Al}$ alloys in $\mathrm{T} 4$ temper leads to strengthening by a combination of the G.P zone and $\delta^{\prime}\left(\mathrm{Al}_{3} \mathrm{Li}\right)$ precipitates [7]. The alloy in this temper displays a rapid and strong naturally aging response, even without prior cold working. For example, the tensile strength of Weldalite grade alloy in the T4 temper is $20 \%$ greater than that of the leading, weldable alloy AA2219 in the T87 temper [8]. Other noteworthy characteristics of these substances include low electrical conductivity, high thermal conductivity and high resistance to thermal degradation. Unlike other chemicals, all varieties are chemically very stable (inactive) and don't change their chemical status over long time and distance without resting. PCBs are non-polar and are thus soluble in non-polar environments like in diethyl ether, dichloromethane, chloroform, petroleum ether and hexanes, but not soluble in polar environments like water. Moreover, due to the whole set of properties, these molecules have low flash point and no fire point. Although there are no known natural sources of PCBs in the nature, the widespread prevalence are related to commercial manufacture, industrial use, storage and disposal. The general chemical structure, including the conventional numbering of

\section{Publication History:}

Received: July 25, 2015

Accepted: September 19, 2015

Published: September 21, 2015

Keywords:

Transformer oils, PCBs, Total Halogens/Chlorine, Contamination

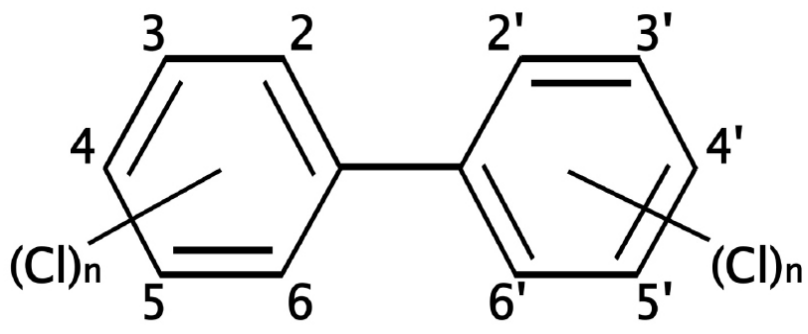

Figure 1: Structure and numbering for PCBs [5].

Between 1930 and 1980 PCBs were used in industrial applications such as transformers, capacitors, heat transfers, hydraulic systems, lubricants, pesticide extenders, sealant, paints, adhesives, flame retardants and plastics. PCBs were sold under a variety of trade names, the most commons were Aroclor, Apirolio, Phenoclor, Pyroclor, Inerteen, Colphe and Kanaclor and the total amount produced world-wide is estimated at 1.5 million tons [6]. PCBs were mainly used as coolants and insulating fluids in electrical equipment like transformers and capacitors, the so-called closed systems. The International Agency for Research on Cancer and the Environmental Protection Agency (EPA) has classified PCBs as a Group B2, probable human carcinogen [7]. And because of their classification as a human carcinogen, the further manufacture of PCBs was banned by the

"Corresponding Author: Mr. Volkan Pelitli, The Scientific and Technological Research Council of Turkey, Marmara Research Center, Environment and Cleaner Production Institute, Kocaeli/Turkey; E-mail: volkan.pelitli@tubitak.gov.tr

Citation: Pelitli V, Doğan O, Köroğlu HJ (2015) Transformer Oils Potential for PCBs Contamination. Int J Metall Mater Eng 1: 114. doi: http://dx.doi. org/10.15344/2455-2372/2015/114

Copyright: @ 2015 Pelitli et al. This is an open-access article distributed under the terms of the Creative Commons Attribution License, which permits unrestricted use, distribution, and reproduction in any medium, provided the original author and source are credited. 
Citation: Pelitli V, Doğan O, Köroğlu HJ (2015) Transformer Oils Potential for PCBs Contamination. Int J Metall Mater Eng 1: 114. doi: http://dx.doi. $\operatorname{org} / 10.15344 / 2455-2372 / 2015 / 114$

Page 2 of 8

United States Congress and by the Stockholm Convention on Persistent Organic Pollutants. In Europe, the use of PCBs as a raw material or chemical intermediate has been banned since 1985 (85/467/EEC, 6th amendment to Directive 76/769/EEC) [8].

Currently the production of PCBs is prohibited today, those products manufactured before the prohibition are still used and contamination still continues. Transformers and capacitors, which were manufactured prior to 1970 s, may contain certain levels (ppm) of PCBs in insulating oils. Therefore, all holders of electrical equipment should determine whether their equipment contains PCBs or verify the absence of PCBs. Although the quantification of PCBs in electrical transformers may seem simple, the diversity of congeners, as well as their similar physical and chemical properties makes PCBs difficult compounds to analyses based on the limited information presently gathered and published in the scientific literature [9] In order to determine potential threats, identify the probability of occurrence and the potential impact to public and environmental health, transformers that come out of service must sampled and analyzed. In this study the investigation was carried out on twenty transformers. These transformers operate for long years, different loads and operation condition in Turkey. The levels of PCBs expressed as sum of the concentrations of six indicators $(28,52,101,138,153$ and 180) which were suggested by Commitment Bureau of Reference (BCR) [10]. And the samples were also tested for the presence of the chlorine and total halogens and comparedwith Category I Waste Oil in the Regulation on Control of WasteOils [11].

\section{Experimental}

\section{Sample collection}

Twenty samples of transformer oils from various regions of Power Station were collected in Turkey. Sampling activities were conducted in accordancewith applicable European Union: Council Directive 96/59/ EC sampling requirements [12]. Before sampling the transformer oil, the working zone was typically marked by signs and disconnecting power by electrician. And, prior to sampling, transformers were inventoried of which were suspected to be contaminated with PCBs.

\section{Sample preservation and storage}

All samples were stored in the dark at $4 \mathrm{oC}$ until they were processed in the laboratory. No other preservatives were added to the samples and analyses were completed in 2 days after sample preparation.

\section{Glassware}

All the glassware was washed with acetone and n-Hexane, ovendried for at least $8 \mathrm{hr}$ at $100^{\circ} \mathrm{C}$ and allowed to cool under nitrogen atmosphere before use. After cooling, the glassware was sealed with plugs and/or Teflon tape to prevent the accumulation of dust or other contaminants.

\section{PCBs}

\section{Instrumentation}

An Agilent 6890 Series GC (USA) equipped with a liquid autosampler, split/splitless inlet and with Electron capture detector was used in the experiment. Data was acquired and processed by Agilent ChemStation. The ChemStation was operated at a data acquisition rate of $10 \mathrm{~Hz}$. The detector acquisition rate is fast enough to record peak changes in the detector. The software performs system control, database management, data handling and output.

\section{Chemicals}

All chemicals were of reagent grade and were used without further purification. PCB congeners $(28,52,101,118,153$ and 180) standards were obtained as individual stocks from Supelco, Accustandard and Ultra Scientific. All stock solutions were stored in the dark in a freezer. Supelco SCX SPE cartridges were obtained from Sigma-Aldrich and silica gel was also from Merck Co. Analytical grade hexane (\% 99) was purchased from Merck.

\section{Extraction procedure}

Solid phase extraction procedure was applied to remove the interfering components of the complex matrices in order to obtain a cleaner extract containing the analytes of interest. According to EN 12766, acidified silica and silica adsorbent is used. The SPE cartridges were activated by Hexane. Then transformer oil samples were passed through cartridge using Supelco vacuum manifold system. The extracts were concentrated for about 5 minutes under nitrogen gas to remove excess solvent and before GC-ECD analysis extracts transferred to an auto sampler vials containing $100 \mu \mathrm{L}$ insert. Concentrated extracts included PCB 30 and 209 internal standards prior to extraction. Qualitative and quantitative analyses were done by comparison with internal standards. This method has shown a very good recovery $(80-110 \%)$ and accuracy for investigated samples.

\section{Analysis}

A gas chromatograph wasequipped with a HT-8 $(25 \mathrm{~m}, 0.22 \mathrm{~mm}$, 0.25 ID) capillary column and ECD was connected to Agilent 6890 integrator. The analysis was carried out using mass range from 50 to $500 \mathrm{amu}$ and in Scan mode (EI) [13]. Samples of $1 \mu \mathrm{l}$ were injected in split mode with a split ratio $1: 10$. The column was temperature programmed at $75-300^{\circ} \mathrm{C}$ with a $10 \mathrm{oC} / \mathrm{min}$ rise. The detector temperature was set at $350^{\circ} \mathrm{C}$ and the injector temperature at $300^{\circ} \mathrm{C}$. Helium was used as carrier gas at $1.0 \mathrm{~mL} / \mathrm{min}$ flow.The limit of detection of the method was below $0.01 \mathrm{ppm}$.

\section{Quantitation}

A calibration curve obtained from standards was used for the quantification of individual PCBs isomers. Before each run GC-ECD system performance and calibration are verified for all analytes.

\section{Total halogens and chlorine}

For chlorine and total halogensanalysis, the transformer oils were treated according to EPA Method5050 (bomb preparation) and analyzed according to EPA Method9056A (ion chromatography).A Dionex ICS 1000 ion chromatography with Dionex DS6 conductivity detector, Dionex isocratic pump and Dionex AS9-HC $4 \mathrm{~mm}$ columnwas used for the analysis.Total Halogen Content in oils was expressed as sum of chlorine (Cl-), fluorine (F-) and bromine (Br-) in $\mathrm{ppm}$. The limits of quantitation for $\mathrm{Cl}-, \mathrm{F}$ - and $\mathrm{Br}$ - were $0.2,0.02$ and $0.1 \mathrm{ppm}$, respectively.

\section{Results}

The regulatory guidelines classify materials with levels equal to or greater than 50 parts per million $(\mathrm{mg} / \mathrm{kg}$ ) of PCB content to be a controlled hazardous waste material and require special handling and disposal by law. Generally, transformer oil is a mixture of aliphatic, alicyclic, and polynuclear aromatic hydrocarbons but in some cases may contain only PCB mixtures. Because of their highly regulated use and disposal, all oils from transformers need to be sampled 
Citation: Pelitli V, Doğan O, Köroğlu HJ (2015) Transformer Oils Potential for PCBs Contamination. Int J Metall Mater Eng 1: 114. doi: http://dx.doi. org/10.15344/2455-2372/2015/114

Page 3 of 8

prior to disposal of the oil and analyzed to determine PCBs content. Because of the obligation, different fundamental machines were used to investigation of PCBs in transformer oils. The transformer oil survey results showed that for the most of the samples, no detectable PCBs were observed. The results of peak pattern analysis have explained that except sample 1-3, 4 from 20 transformer oils were not contaminated with PCBs. But sample 1 was exceed the legal limit of $50 \mathrm{ppm}$. The sample 1 showed an average PCBs content of $150 \mathrm{ppm}$ and was considered a hazardouswaste and must treated accordingly. The results are shown in Table 1. The reported levels raise concern and take appropriate measures to prevent their environmental dispersion in global environment.

\begin{tabular}{|c|c|c|}
\hline Sample No & Report Limit, ppm & Result, ppm \\
\hline 1 & 0.01 & 150 \\
\hline 2 & 0.01 & 0.06 \\
\hline 3 & 0.01 & 1.37 \\
\hline 4 & 0.01 & ND \\
\hline 5 & 0.01 & ND \\
\hline 6 & 0.01 & ND \\
\hline 7 & 0.01 & ND \\
\hline 8 & 0.01 & ND \\
\hline 9 & 0.01 & ND \\
\hline 10 & 0.01 & ND \\
\hline 11 & 0.01 & ND \\
\hline 12 & 0.01 & ND \\
\hline 13 & 0.01 & ND \\
\hline 14 & 0.01 & ND \\
\hline 15 & 0.01 & ND \\
\hline 16 & 0.01 & ND \\
\hline 17 & 0.01 & ND \\
\hline 18 & 0.01 & ND \\
\hline 19 & 0.01 & ND \\
\hline 20 & 0.01 & ND \\
\hline \multicolumn{3}{|c|}{ ND - Not detected } \\
\hline
\end{tabular}

The total halogens and chlorine results of twenty oil samples are shown in Table 2. The total halogens and chlorine values range is from 10 to 337.7 and 10 to 321.8 , respectively. There was a significant relationship PCBs and total halogens and chlorine.

The significant relationship between PCBs and total halogens and chlorine suggests that these ions have significant effect on the persistence and concentration of PCBs.

Furthermore, the characteristics of contaminated transformer oils were comparedwith Waste Oil Categories in the Regulation on Control ofWasteOils (Offical Gazette No. 26952) in Turkey[11].For this purpose, PCBs,total halogens and chlorine results compared with the limit values.The pollutants in sample 1 are upper the limit values given in the Regulation on Controlof Waste Oils for Category I. The Category I Waste Oil is available for recovery through refining and regeneration as feedstock or suitable for useas supplementary fuel in the facilities licensed by the Ministry of the Environment and Urbanization such ascement and/or lime kiln. The comparison of contaminated transformer oils and Category I Waste Oil are given in Table 3. According to this table, it was shown thatsample 1 results (PCBs, total halogens and chlorine) are over the limit values of Category I Waste Oil.

\begin{tabular}{|l|l|l|l|l|}
\hline $\begin{array}{l}\text { Parameters } \\
(\mathrm{ppm})\end{array}$ & Sample 1 & Sample 2 & Sample 3 & $\begin{array}{l}\text { Limit values } \\
\text { for Category 1 } \\
\text { Waste Oil }\end{array}$ \\
\hline PCBs & 150 & 0.06 & 1.37 & $<10$ \\
\hline Total Halogens & 337.7 & 68 & 108.4 & $<200$ \\
\hline Chlorine & 321.8 & 83.4 & 93.1 & $<200$ \\
\hline
\end{tabular}

Table 3: The comparison contaminated transformer oils and Category I Waste Oil.

PCB-containing transformer from which sample 1 was taken is located in electricity generating facility (power plant) in unincorporated. The transformer can be seen in Figure 2. The owner of the PCB-transformer must take measures as soon as practically and safely possible to contain and control any potential releases of PCBs. In any case the newly-identified PCB Transformer immediately registers in the national database and must be disposed of in a carefully controlled manner in accordance with regulations administered by Ministry of Environment and Urbanization (MEU).

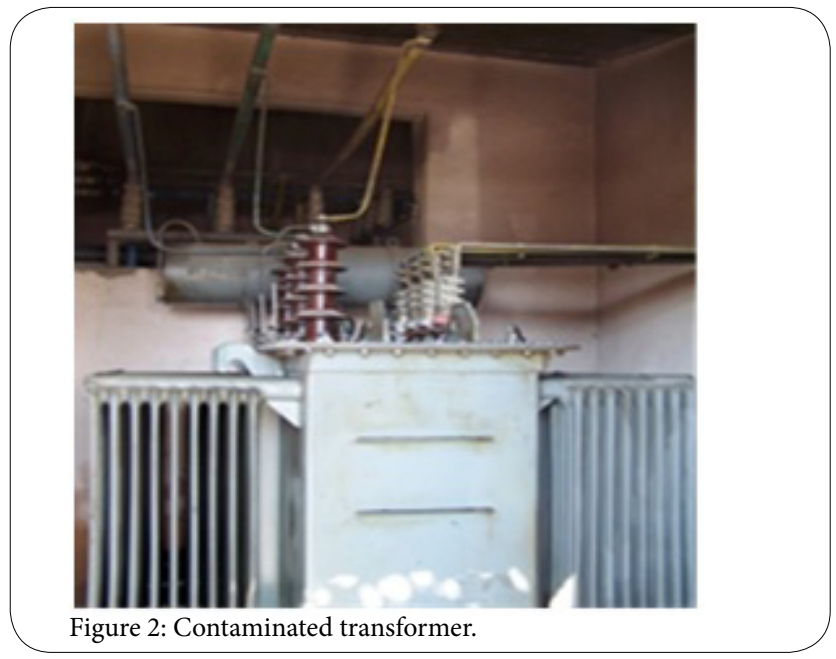

Four major PCB disposal methods have been authorized by the MEU. These are as follows:

1. High temperature combustion in incinerations and high efficiency boilers (if PCBs are not burnt at high enough temperatures, dioxin is formed and this substance, which is even more toxic than the PCBs, would be released into the atmosphere),

2. Chemical dechlorination,

3. Landfilling and

4. Alternate disposal techniques which achieve a level of performance equivalent to an approved incinerator or boiler.

These highly specialized techniques are required to permanently eliminate or reduce the threat of contamination from PCBs. Such technical specifications and specific conditions vary depending on the profession to destroy PCBs on a tonnage scale.

\section{Conclusion}

Twenty transformer oils were collected and analyzed as a main source of PCBs into environment in Turkey. The levels of PCBs in transformer oils were ranged from $<0.01$ to $150 \mathrm{ppm}$. It was determined that PCBlevels of one sample are overthe limit values of $50 \mathrm{ppm}$. 
Citation: Pelitli V, Doğan O, Köroğlu HJ (2015) Transformer Oils Potential for PCBs Contamination. Int J Metall Mater Eng 1: 114. doi: http://dx.doi. org/10.15344/2455-2372/2015/114

Additionally, according to the Regulation on Control of Waste Oils, it would be hazardous for the environment and the public health when it would use as feedstock and/or fuelfor the reason of PCBs, total halogens and chlorine content.On the basis of the investigation performed, the experimental results have shown that PCBs still present in Turkey. It appears that small PCB containing transformers are mainly use in electrical network. From the environmental point of view the releases of PCBs in the transformer should be taken into consideration for end of life management. Because, declining but widespread PCB contamination is present throughout the electrical industry.

\section{Competing Interests}

The authors have no competing interests with the work presented in this manuscript.

\section{Author Contributions}

All the authors substantially contributed to the study conception and design as well as the acquisition and interpretation of the data and drafting the manuscript.

\section{Acknowledgements}

We wish to thank Mr. Hüseyin Demir and Baki Kalayfor excellent technical assistance during experimental work.

\section{Funding}

This study was funded by TUBITAK, The Scientific and Technological Research Council of Turkey, scientific research project with the grant number 107G007.

\section{References}

1. Alford-Stevens AL, Budde WL, Bellar TA (1985) Interlaboratory study on determination of polychlorinated biphenyls in environmentally contaminated sediments. Anal Chem 57: 2452-2457.

2. Princeton University (2014) Polychlorinated biphenyl.

3. Stewart AG, Adams R, Keenan R, Kowalczyk G, Lamont H, et al. (2010) Remembering Sharon and Rebecca-investigating leukaemia and chemical pollution in Cheshire, Chemical Hazards and Poisons Report, Health Protection Agency, pp. 15-17.

4. World Health Organization (WHO), Polychlorinated Biphenyls (PCBs), 2011.

5. Ahlborg UG, Hanberg A, Kenne K (1992) Risk assessment of polychlorinated biphenyls (PCBs), Nord 1992:26, Nordic Council of Ministers, Nord 1992:26, Nordic Council of Ministers ISBN 9291200751, pp. 1-99.

6. SRI Instruments (2014) PCB GC System.

7. Environmental Protection Agency (EPA) (2014) Polychlorinated Biphenyls (PCBs).

8. Council Directive 85/467/EEC of 1 October 1985 amending for the sixth time (PCBs/PCTs) Directive 76/769/EEC on the approximation of the laws, regulations and administrative provisions of the Member States relating to restrictions on the marketing and use of certain dangerous substances and preparations.

9. Egolf DS, Jurs PC (1990) Structural analysis of polychlorinated biphenyls from carbon-13 nuclear magnetic resonance spectra. Anal Chem 62: 17461754.

10. Wells D, Maier E, Griepink B (1993) Environmental Analytical Chemistry of PCBs, Vol 16, Albaigés J, Ed., Gordon and Breach Sci. Pub, Singapore 89-100.

11. Ministry of Environment and Forest, Regulation on Control of Waste Oils 26952, Turkey, 2008.

12. Council Directive $96 / 59 / E C$ of 16 September 1996 on the disposal of polychlorinated biphenyls and polychlorinated terphenyls (PCB/PCT).

13. Mang-Kei C, Szelewski M (2000) Agilent Tech Inc, Application Gas Chromatography. 